\title{
Paediatric crossword puzzle 8 (REPRODUCED)
}

Manouri P Senanayake ${ }^{1}$

Sri Lanka Journal of Child Health, 2010; 39: 72

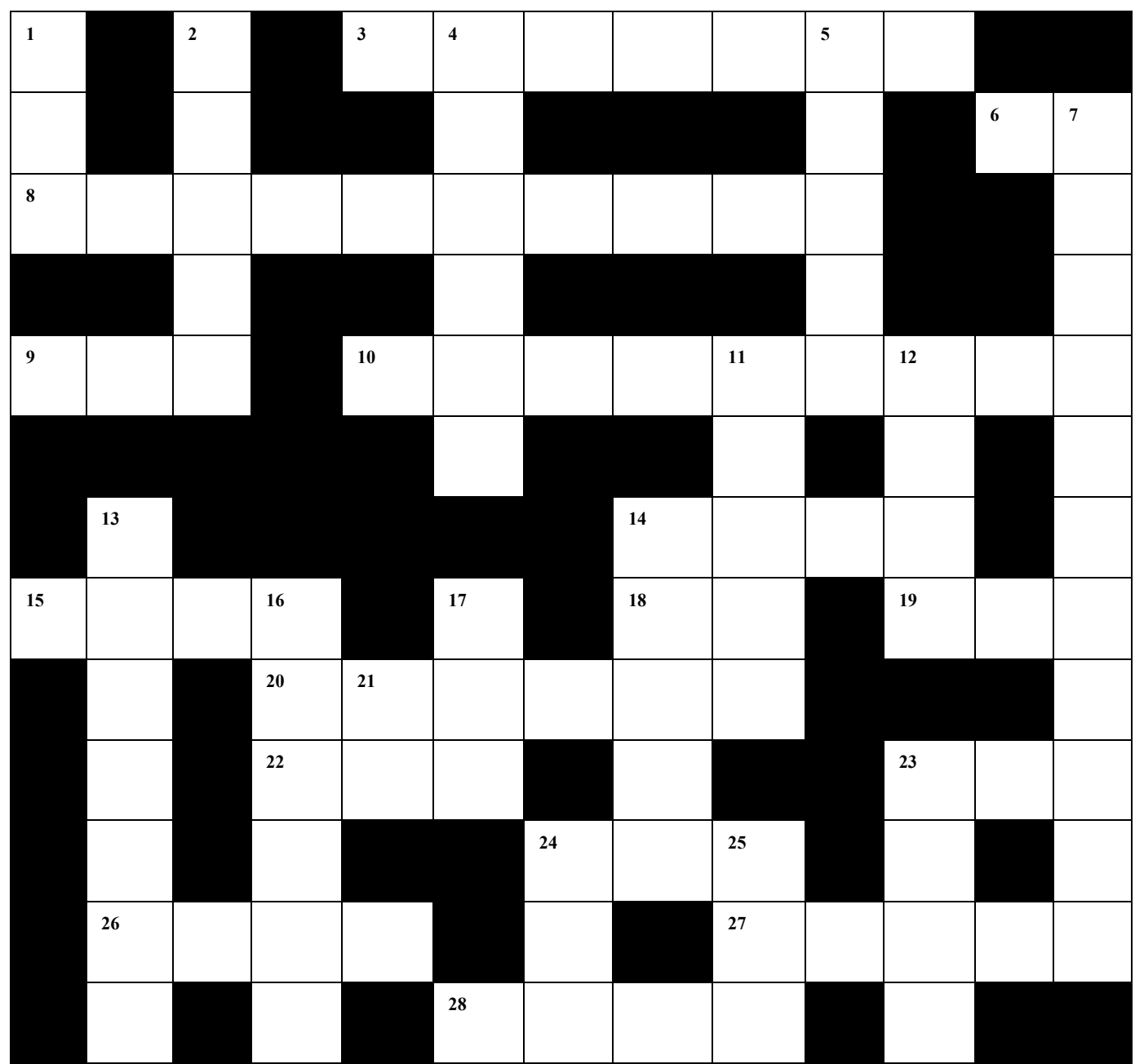

\section{THIS CROSSWORD IS REPEATED AS THE EARLIER GRID HAD TECHNICAL ERRORS}

Across

3 a nipple abnormality

6 an opening ( latin )

8 medication that reduces portal hypertension

9 indicates an underlying spina bifida

10 milk rich in immunoglobulins

14 best avoided in atopic dermatitis

15 treatment strategy for tuberculosis

18 _ mian bones

19 examination under anaesthesia (abbrv)

20 curdles milk

22 measure of poverty line

23 a predictor of metabolic syndrome in adulthood

24 provides confirmatory evidence of hypsarrhythmia

26 measles, rubella and oral polio vaccines

27 chronic constipation leads to enlargement

28 cot death

\section{Down}

1 UN agency representing 192 countries

2 ocular lesion associated with vitamin A deficiency

4 retinal pigment named after the colour rose-pink (Greek)

5 adverse outcome

7 improves cognition

11 a feeding device

12 sexual abuse

13 part of Waldeyer's ring

14 novel H1N1 influenza

16 the first vitamin deficiency to be described

17 reflex that excludes cataracts

21 valvular defect causing low volume pulse

23 inspissation causes cholestasis

24 program that controls six childhood infections

25 an assessment of conscious state

${ }^{1}$ Professor in Paediatrics, Faculty of Medicine, University of Colombo

See September 2010 issue for answers 